\title{
Update on Statistical Methods for Interpreting Horticultural Data: An Introduction to the Colloquium
}

\author{
Richard Marini \\ Department of Horticulture, The Pennsylvania State University, University Park, PA 16802
}

\begin{abstract}
Biological statistics is a relatively young science and, although it was initially developed to aid agricultural researchers, it is now used in nearly all fields of research. Horticulturists were fortunate because one of the first major statistical publications (Field Experiments in Horticulture) was written by T.N. Hoblyns, who appreciated the practical difficulties of horticultural research in field settings. This book was the standard for 20 years, and much of the information is still applicable, but over the years many procedures have been extended. The widespread accessibility of fast computers with large amounts of memory has allowed the rapid improvement of statistical software packages so researchers can perform analyses that are more appropriate than those that were available just 13 years ago. With these new procedures, researchers can extract increas-
\end{abstract}

ing amounts of information from their data. However, the availability of computer-aided statistics has also generated opportunity for misuse, especially in regard to the factors necessary for valid application of the basic procedures, and for interpretation of their results.

Statistical analyses first appeared in ASHS publications in the early 1940s, and became common by the early 1960s. Statistical analysis of data is now required for publication in most agricultural journals. Most horticulture graduate students take one or two statistics courses, then rely on their notes and textbooks as references for the duration of their careers. Researchers attend professional meetings and read journals to remain current in their disciplines, but rarely attempt to keep up with rapid changes in the field of statistics. More than 15 years have passed since ASHS had a colloquium on statistics, so this colloquium is long overdue. Before developing the program for this session, associate editors from the Journal and HortScience were asked for suggested topics. Everyone who responded indicated that we need more programs on statistics. There were many very good suggestions. Some suggested topics were too broad and would require several hours to cover, whereas others were too narrow and would be of interest to a limited audience. It is obvious that ASHS members would like to have more programs on statistics and I hope more will be planned in the near future. The topics selected for this colloquium should be of interest to nearly every horticultural researcher, and will provide a modern approach to analyzing and interpreting data from traditional experimental designs. 